\title{
Compaction behaviour of mannitol-cocoa powder mixtures and their resulting tablet strength and disintegration characteristics
}

\author{
${ }^{1}$ Mukri, A.K., ${ }^{1}$ Tan, J.H., ${ }^{1, *}$ Tahir, S.M., ${ }^{2}$ Anuar, M.S. and ${ }^{1}$ Yusoff, S.M. \\ ${ }^{1}$ Department of Mechanical and Manufacturing Engineering, Faculty of Engineering, Universiti Putra \\ Malaysia, 43400 UPM Serdang, Selangor Darul Ehsan, Malaysia. \\ ${ }^{2}$ Department of Process and Food Engineering, Universiti Putra Malaysia, 43400 UPM Serdang, Selangor \\ Darul Ehsan, Malaysia.
}

\begin{abstract}
Article history:
Received: 5 May 2020

Received in revised form: 12

July 2020

Accepted: 16 December 2020

Available Online: 18 April

2021
\end{abstract}

Keywords:

Cocoa,

Mannitol,

Compaction,

Food tablets,

Tablet strength,

Tablet disintegration

DOI:

https://doi.org/10.26656/fr.2017.5(S1).038

\begin{abstract}
Cocoa powder is an important ingredient in the confectionery industry and, mannitol is an alternative sugar alcohol. In this work, mannitol powder was mixed with cocoa powder and compacted into tablet form via the uniaxial die compaction process. The frictional, compaction, tablet mechanical and disintegration properties were studied due to their importance in characterizing the behaviour of the tablets during processing and its final product characteristics at varying mannitol contents. The composition of mannitol in the mannitol-cocoa tablet varied at $95 \% \mathrm{w} / \mathrm{w}, 50 \% \mathrm{w} / \mathrm{w}$ and $5 \% \mathrm{w} / \mathrm{w}$, while pure $100 \% \mathrm{w} / \mathrm{w}$ mannitol and cocoa tablets were set as controls. The compaction pressures used in making the tablets varied at $37.67 \mathrm{MPa}, 75.34 \mathrm{MPa}, 113.01 \mathrm{MPa}, 150.68 \mathrm{MPa}$ and $188.35 \mathrm{MPa}$. The compaction behaviour of the powder during the compaction process was evaluated using the plastic work and the maximum ejection stress values. The tablet strength was determined using the tensile strength method and tablet disintegration study was also conducted. The results showed that the increase in the compaction pressures increased the plastic work, maximum ejection pressure, tablet strength and also its disintegration time. The tablet formed having $95 \% \mathrm{w} / \mathrm{w}$ mannitol composition exhibited the highest plastic work value of $10.32 \pm 0.01 \mathrm{~J}$, highest maximum ejection pressure value of $4.4 \pm 0.06 \mathrm{MPa}$, highest tensile strength value of $1.06 \pm 0.04 \mathrm{MPa}$ and shortest disintegration time of $171 \pm 51 \mathrm{~s}$ amongst the three different mannitol compositions studied. Meanwhile, the effects of mannitol composition in the tablet on these observed responses were also dependent upon the compaction pressures used during tablet formation. In conclusion, the addition of mannitol improved the tablet strength and shorten the disintegration time in the experimental range employed in this study.
\end{abstract}

\section{Introduction}

Cocoa is one of the major crops in Malaysia. The planted area for cocoa in Malaysia was approximately 15008 ha whereby about $810 \mathrm{Mt}$ of cocoa was produced in 2018 (Department of Agriculture Malaysia, 2018). One of the major products from cocoa is cocoa powder (Beg et al., 2017). Cocoa powder is currently utilized in the food industry such as in the production of chocolates, beverages and other chocolate confectionaries (Beg et al., 2017). Specifically, the chocolate confectionery industry saw the highest market growth rate in Malaysia, where it was pointed that a 5\% growth in the market for chocolate tablets were observed (Malaysian-German Chamber of Commerce and Industry, 2016). Tablets are compacted powders which are convenient to be handled and consumed by the public. This was also in line with the trend of increasing research of tableted food powders. Some of the previous researchers have studied the compaction properties of food powders such as those of sweet potato and stevia powders (Shamsudin et al., 2012), roselle powders (Shamjuddin et al., 2014) and recently coffee powders (Jamar et al., 2019). For the case of cocoa powders, Mohamad and co-workers (2013) conducted a detailed fundamental study on the compaction behaviour of binary cocoa-lactose powder mixtures, specifically on their ejection behaviours. Although these cocoa-lactose tablets could potentially be further extended to be formulated into a commercial product, the use of lactose as a sweetener would be unacceptable to lactose intolerance consumers. 
Nowadays, consumer preference for lactose-free foods is becoming a growing trend (Dekker et al., 2019). Therefore, manufacturers are trying to substitute lactose with other sugar molecules apart from glucose and sucrose. One of the alternative sugars that have been researched is mannitol. Mannitol is commonly used in chewing gums, sugar-free candies and has a relatively low glycemic index hence suitable as part of a diabetic diet (O'Donnel and Kearsley, 2012). Although there were various commercially available sugars in the market, not all of them were suitable to be used in the making of tablets. The sugars must have appropriate powder physical properties such as flowability to avoid problems during the tabletting or compaction process. Frictional characteristics displayed by the sugars during the compaction process should be at a minimum in order to minimize tool wear and production downtime. In addition, the tablets must have sufficient mechanical strength to withstand handling during processing and by the consumers to avoid problems such as breakage. They should also have the ability to disintegrate into the primary particles before dissolving in the targeted fluid environment such as water or in the mouth. A number of sugar-based excipients specifically designed to be used in the tablet formulation have been researched and produced commercially in the industry. Therefore, it is the aim of this work to explore the use of sugar alcohol, which is mannitol sugar to be mixed with cocoa powders to form tablets. In this current study, the important parameters that will be studied are the compaction behaviour of the binary cocoa-mannitol powder mixture during the compaction process, the resulted tablet mechanical integrity and its disintegration characteristics.

\section{Materials and methods}

\subsection{Raw materials and sample preparation}

The cocoa powder used was obtained from Cargill, Malaysia (10/12 DL72). Meanwhile, the mannitol powder used was of pharmaceutical excipient grade, but the source could not be included in this article due to proprietary reason. Several important physical properties of the mannitol powder could be found in another work (Mohd Radzuan et al., 2020). The cocoa and mannitol powders were mixed at equal and extreme ratios, which were $95 \%$ w/w cocoa $+5 \%$ w/w mannitol (labelled as sample C95M5), 50\% w/w cocoa $+50 \% \mathrm{w} / \mathrm{w}$ (labelled as sample M50C50) and 5\% w/w cocoa $+95 \% \mathrm{w} / \mathrm{w}$ (labelled as sample C5M95) mannitol using a laboratory powder mixer (Glas-Col, USA). Pure cocoa (labelled as sample C100) and mannitol (labelled as sample M100) powders were also being compacted into tablets and as the controls in this study.

\subsection{Compaction experiment}

A total of $0.5 \mathrm{~g}$ of the powder materials were weighed using a balance (PA413, Ohaus, USA) and inserted into a $13 \mathrm{~mm}$ stainless steel die set (Specac, UK). The powder inside the die was then compacted using a universal testing machine (model 3382, Instron, USA) producing $13 \mathrm{~mm}$ diameter, $0.5 \mathrm{~g}$ flat-face cylindrical tablets. The tablets were formed at various compaction pressures of $37.67 \mathrm{MPa}, 75.34 \mathrm{MPa}, 113.01$ MPa, $150.68 \mathrm{MPa}$ and $188.35 \mathrm{MPa}$ (Radzali et al., 2018). A constant compaction speed of $0.1 \mathrm{mms}^{-1}$ was used for both the loading and the unloading stages of the compaction process (Radzali et al., 2018). The forcedisplacement data obtained during the compaction process was recorded via software (Bluehill, Instron, USA).

\subsection{Compaction behaviour}

Based upon the appropriate integration to find the area under the force-displacement data recorded during the loading and unloading stages of the compaction process, the plastic work could then be calculated (Shamsudin et al., 2012). The plastic work is a common method to quantify the amount of plastic deformation occurring during the loading stage of the compaction process (Alderborn and Nystrom, 1996; Al-Ibraheemi Mousa et al., 2013). In addition, the maximum ejection pressure of the tablet during the ejection stage was also used as a quantitative measure of the frictional resistance to tablet movement when the tablet was being extruded from the die cavity (Yaakub et al., 2018; Radzali et al., 2018). A relatively higher plastic work value generally accounts for relatively higher plastic deformation of the particles and higher maximum ejection pressures represented higher frictional resistance to tablet motion during ejection.

\subsection{Tablet mechanical strength}

The tablet mechanical strength was evaluated using the diametrical tensile strength test or commonly known as the Brazilian test (Fell and Newton, 1970; Alderborn and Nystrom, 1996; Shamsudin et al., 2012). The tablet was placed on the horizontal flat surface under the crosshead of the universal testing machine (model 3382, Instron, USA). The crosshead was then programmed to compress the tablet until it fractured diametrically. The force-displacement data was recorded using software (Bluehill, Instron, USA). The tablet diametrical tensile strength could then be estimated using the following equation:

$$
\sigma_{t}=\frac{2 P}{\pi D t}
$$


Where $P$ is the breaking force $(\mathrm{N}), D$ is the tablet diameter (m) and $t$ is the tablet thickness or height (m).

\subsection{Tablet disintegration}

The tablet disintegration was conducted using a paddle apparatus dissolution tester (Pharmatest, Germany). The tablet was placed inside a vessel containing $900 \mathrm{~mL}$ distilled water. The temperature was maintained at $37^{\circ} \mathrm{C}$ and the paddle rotation was maintained at $100 \mathrm{rpm}$. The disintegration process was physically observed, and the time taken for the tablet to disintegrate under these conditions was recorded (Radzali et al., 2018).

\section{Results and discussion}

When the compaction pressure was applied in the loading stage of the compaction process, the powder bed would be subjected to a decrease in volume as the particles started rearranging into a closer packing and became fragmented or deformed either plastically or elastically or combination of these main deformation behaviours. The plastic and elastic components of the deformation of the particles during the loading stage could be viewed from the force-displacement data obtained during the loading and unloading stages of the compaction process, where the permanent bed deformation was taken as approximating to the plastic deformation component of the particles whilst the recoverable particle bed height upon the removal of the compaction pressure represented the elastic component of the deformation during the loading stage of the compaction process. The plastic deformation of the particle bed during the loading-unloading stages of the compaction process could then be estimated by the appropriate integral of the fore-displacement data obtained in these stages (Alderborn and Nystrom, 1996). Based on Figure 1, it could be observed that the plastic work increased with increasing values of the compaction pressure. This indicated that permanent particle bed deformation during the loading stage increased with the application of a higher compaction pressure onto the particle bed, similarly, indicated in other recent works involving the compaction of other materials such as coffee powder (Jamar et al., 2019), carboxymethylcellulose powder (Radzali et al., 2018), lactose-sodium starch glycolate binary powder mixture (Yaakub et al., 2018), stevia and sweet potato powder (Shamsudin et al., 2012). The increase in the plastic deformation would theoretically lead to the increase in the inter-particulate bond formation thus forming a more mechanically coherent tablet. However, it must be noted that the elastic recovery of the tablet was only in the vertical direction ie. in its height but it was still confined within the die, where it could not radially expand during the compaction process. The tablet would further release its stored elastic energies during the subsequent ejection process of the tablet from the die (Anuar and Briscoe, 2010). The plastic work values for the different compositions also showed some dependencies on the compaction pressure used. For example, it could be seen in Figure 1 that at the medium value of $113.01 \mathrm{MPa}$ compaction pressure, the plastic works for all the different compositions were nearly similar. But the plastic work values differed at the lower and higher compaction pressures above this point. The addition of mannitol decreased the plastic work values for at the lower compaction pressures of $37.67 \mathrm{MPa}$ and 75.34 MPa respectively but increased the plastic work values for the higher compaction pressures of $150.68 \mathrm{MPa}$ and 188.35 MPa. Therefore, the effects of the addition of mannitol to the plastic work values were dependent upon the compaction pressure, where different resulting effects were observed at the lower and higher values of the compaction pressures utilized in this work. This indicated a plausible decreased in the tablet plastic deformation upon the addition of mannitol at the lower compaction pressures of $37.67 \mathrm{MPa}$ and $75.34 \mathrm{MPa}$. Meanwhile, the lowest plastic work values were obtained at the lowest compaction pressure of $37.67 \mathrm{MPa}$ for M100 and M95C5 tablets that contains the pure and highest amount of mannitol composition. Both set of tablets also yielded the highest plastic work values at the highest compaction pressure of $188.35 \mathrm{MPa}$. Equal amounts of mannitol and cocoa composition in the tablet (M50C50) resulted in having plastic work values between those by containing highest mannitol (M95C5 and M100 tablets) composition and those containing lowest mannitol composition (C95M5 and C100 tablets).

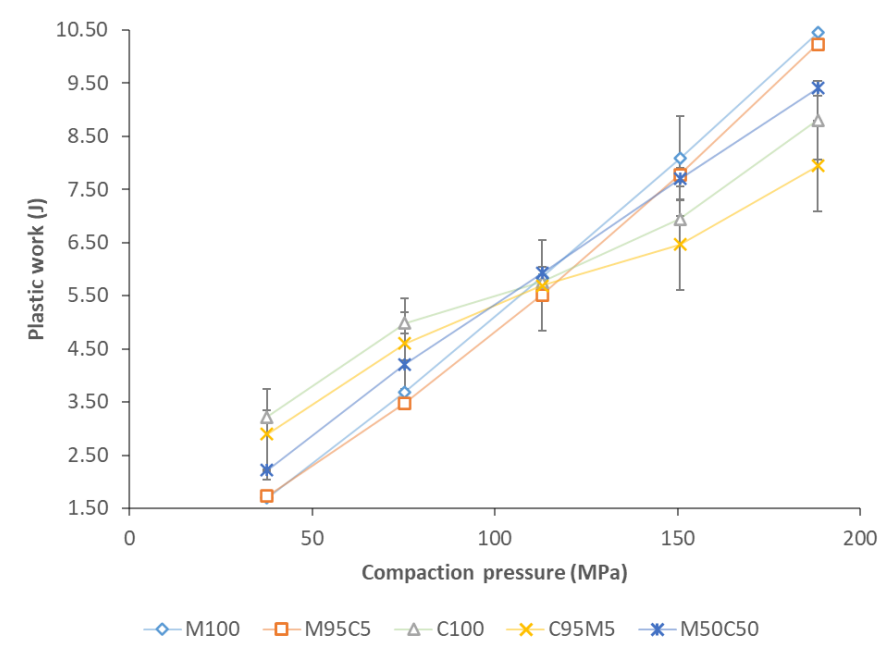

Figure 1. Calculated plastic work values for various cocoamannitol tablet compositions at different compaction pressures.

The maximum pressure needed to extrude the tablet from the die was used as the friction indicator in this 
work. The maximum ejection pressure was the highest force recorded when ejecting the tablet from the die divided by the cross-sectional area of the tablet. According to Figure 2, the force needed to push the tablet out from the die increased with the increasing compaction pressure used during tablet formation for tablets containing at least 50\% w/w mannitol (M50C50). At a higher amount of mannitol in the tablet formulation (M95C5) and for pure mannitol tablets, the increased in the maximum pressure with the compaction pressure were more apparent. A trend of increasing maximum pressure with the compaction pressure was also found by previous workers such as in the lactose - sodium starch glycolate tablets (Yaakub et al., 2018) and urea tablets (Shamsudin et al., 2019). A lower amount of mannitol in the tablet formulation (C95M5) and for pure cocoa tablets, no apparent change in the maximum ejection pressure values were seen as indicated in Figure 1. It was also evident that the addition of mannitol increased the frictional resistance to tablet motion during the ejection stage, ie making it harder to push the tablet out from the die. It was postulated that the presence of residual stored elastic energies prior to the ejection of the tablets caused the tablet to exert a radial stress onto the die wall (Anuar and Brisoce, 2009). A number of previous works have studied the existence of the radial die wall stress using a fully instrumented die set (Holzer and Sjorgen, 1979; Kikuta and Kitamori, 1983). This radial stress would then induced a wall shear stress or friction that impeded the tablet motion during the ejection stage of the compaction process (Briscoe and Rough, 1998).

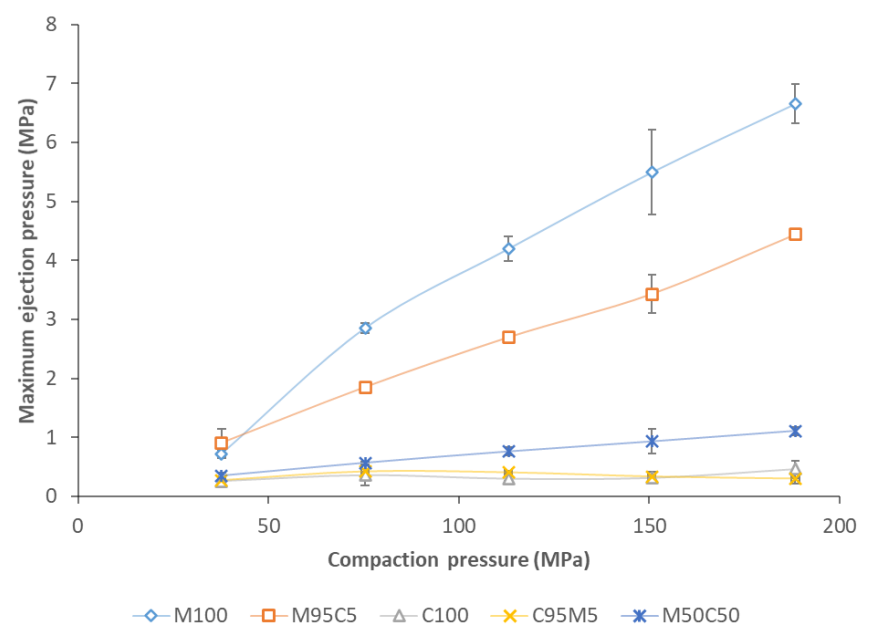

Figure 2. The maximum ejection pressure values for various cocoa-mannitol tablet compositions at different compaction pressures.

The tablets tensile strength increased resulting in relatively stronger tablets when the compaction pressure increased from $37.67 \mathrm{MPa}$ to $113.01 \mathrm{MPa}$ as illustrated in Figure 3 for all tablet compositions. At the higher compaction pressures of $150.68 \mathrm{MPa}$ and $188.35 \mathrm{MPa}$, tablets containing $50 \% \mathrm{w} / \mathrm{w}$ mannitol (M50C50), the lower amount of $5 \% \mathrm{w} / \mathrm{w}$ mannitol (C95M5) as well as the pure cocoa tablets (C100) exhibited relatively constant tensile strength values. Meanwhile, fluctuations in the tensile strength values were observed for the pure mannitol tablets (M100) and approximately linear increased was portrayed by the M95C 5 tablets. It could also be noted the pure mannitol (M100) compacted at 188.35 MPa produced the strongest tablets, followed by the 95\% w/w (M95C5) mannitol tablets at the same compaction pressure. In contrast, the weakest tablet was formed when an equal amount of mannitol and cocoa was present in the tablet formulation (M50C50) at all the compaction pressure used in this work. Even though the higher amount of mannitol in the tablet formulation caused higher frictional effects as shown in Figure 2, the resulting tablets were mechanically stronger than the tablets having lower frictional effects during ejection. Therefore, tablets that contained higher amounts of mannitol (M95C5) and pure mannitol tablets have higher stored elastic energies and the inter-particulate bonding were sufficient to maintain the stored elastic energies producing mechanically stronger tablets.

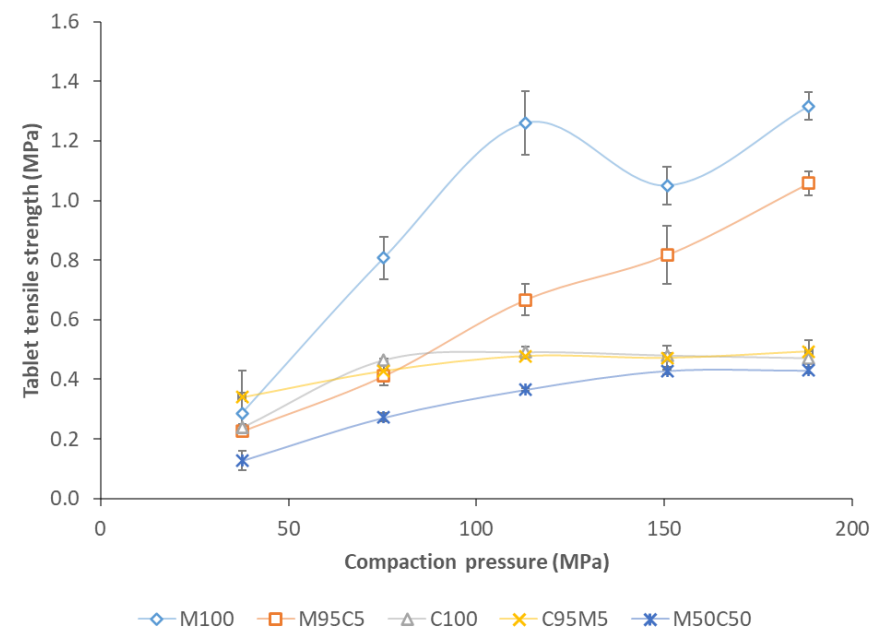

Figure 3. The tablet tensile strength values at different compositions and compaction pressures.

In terms of the ability of the tablet to disintegrate, using higher compaction pressures resulted in extending the tablet disintegration process as shown in Figure 4. This was due to the stronger inter-particulate bonding in the tablet structure as seen earlier in Figure 4 as the compaction pressure was increased. Strong interparticulate bonding was generally associated with the close proximity of the particles to create surfaces for bond formation. Thus, the use of relatively high compaction pressures resulted in closer proximity of the particles thus impeding the penetration of the water molecules during the disintegration process. Therefore, slower disintegration time was observed as seen in Figure 4. Meanwhile, the amount of mannitol in the tablet formulation clearly influenced the disintegration time, where two clearly different order of magnitudes of 
disintegration times were found. Higher amounts of mannitol (M95C5), equal amounts of mannitol and cocoa (M50C50) and pure mannitol (M100) tablets displayed comparatively lower disintegration times than the tablets containing lower amounts of mannitol (C95M5) and pure cocoa tablets $(\mathrm{C} 100)$. The fastest disintegration time was recorded for M95C5 tablets at the lowest compaction pressure of $37.67 \mathrm{MPa}$ whilst the slowest tablet disintegration was for pure cocoa tablets $(\mathrm{C} 100)$ at 113.01 MPa.

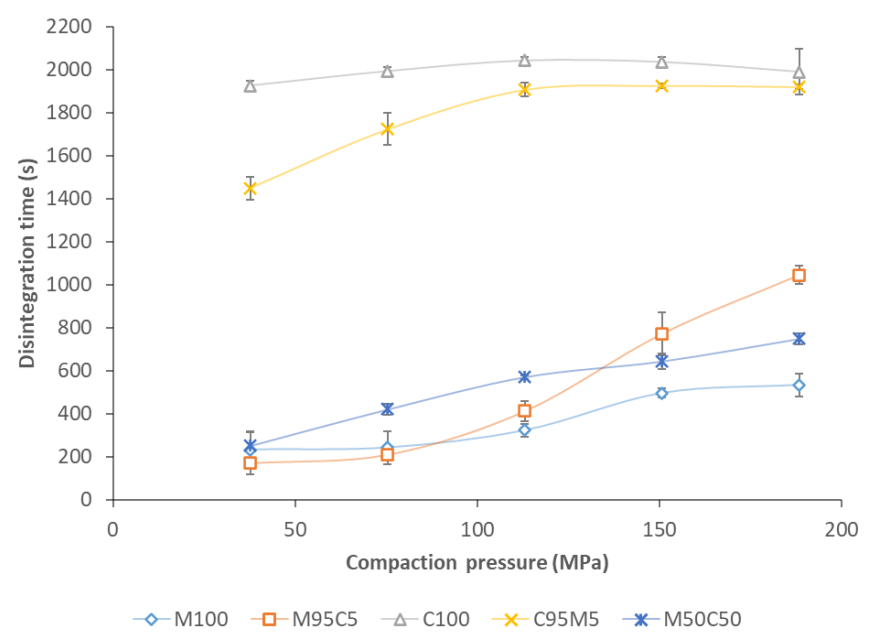

Figure 4. Effects of compaction pressure and composition on tablet disintegration time.

\section{Conclusion}

In general, all the responses which were the plastic work, maximum ejection pressure, tablet tensile strength as well as the tablet disintegration time were found to increase with the increased in the compaction pressure used for tablet formation. Meanwhile, the maximum ejection pressure and the tablet tensile strength were both found to yield higher values for tablets containing higher amounts of mannitol. The tablet disintegration time was also found to be relatively faster at higher amounts of mannitol present. The tablet that contained the highest amount of mannitol (M95C5) exhibited the highest plastic work value of $10.32 \pm 0.01 \mathrm{~J}$, highest maximum ejection pressure value of $4.4 \pm 0.06 \mathrm{MPa}$, highest tensile strength value of $1.06 \pm 0.04 \mathrm{MPa}$ and shortest disintegration time of $171 \pm 51 \mathrm{~s}$ amongst the three different mannitol compositions studied. Overall, the compaction, tablet strength and disintegration characteristics were dependent upon both the amount of mannitol present and the compaction pressure used for tablet formation.

\section{Acknowledgement}

The authors gratefully acknowledging the financial support received from Universiti Putra Malaysia, research grant number: GP-IPS/2018/9654100.

\section{References}

Alderborn, G. and Nystrom, C. (1996). Pharmaceutical Compaction Technology. New York: Marcel Dekker. https://doi.org/10.1201/9780367803971

Al-Ibraheemi, M.Z.A., Anuar, M.S., Taip, F.S., Amin, M.C.I., Tahir, S.M. and Ali, B.M. (2013). Deformation and mechanical characteristics of compacted binary mixtures of plasticv (microcrystalline cellulose), elastic (sodium starch glycolate) and brittle (lactose monohydrate) pharmaceutical excipients. Particulate. Science and Technology, 31(6), 561-567. https:// doi.org/10.1080/02726351.2013.785451

Anuar, M.S. and Briscoe, B.J. (2009). The elastic relaxation of starch tablets during ejection. Powder Technology, 195(2), 96-104. https://doi.org/10.1016/ j.powtec.2009.05.019

Anuar, M.S. and Briscoe, B.J. (2010). Detrimental consequences of paracetamol tablet elastic relaxation during ejection. Drug Development and. Industrial Pharmacy, 36(8), 972-979. https:// doi.org/10.3109/03639041003610807

Beg, M.S., Ahmad, S., Jan, K. and Bashir, K. (2017). Status, supply chain and processing of cocoa - a review. Trends in Food Science and Technology, 66, 108-116. https://doi.org/10.1016/j.tifs.2017.06.007

Briscoe, B.J. and Rough, S.L. (1998). The effects of wall friction on the ejection of pressed ceramic parts. Powder Technology, 99(3), 228-233. https:// doi.org/10.1016/S0032-5910(98)00113-2

Dekker, P.J.T., Koenders, D. and Bruins, M.J. (2019). Lactose-free dairy products: market developments, production, nutrition and health benefits. Nutrient, 11(3), 551. https://doi.org/10.3390/nu11030551

Department of Agriculture Malaysia (2018). Industrial crops statistics. Putrajaya: Department of Agriculture Malaysia.

Fell, J. T. and Newton, J.M. (1970). Determination of the tensile strength of tablets by the diametrical compression test. Journal of Pharmaceutical. Science, 59(5), 688-691. https://doi.org/10.1002/ jps. 2600590523

Holzer, A.W. and Sjogren, J. (1979). Instrumentation and calibration of a single-punch press for measuring the radial force during tableting. International Journal of Pharmaceutics, 3(4-5), 221-230. https:// doi.org/10.1016/0378-5173(79)90005-X

Jamar, A., Anuar, M.S. and Tahir, S.M. (2020). Frictional effects, mechanical strength, and disintegration of coffee mix tablet, effervescent coffee mix tablet and with added lubricant. 
Particulate Science and Technology, 38(7), 892-897. https://doi.org/10.1080/02726351.2019.1666950

Kikuta, J. and Kitamuri, N. (1983). Evaluation of the die wall friction during tablet ejection. Powder Technology, 35(2), 195-200. https:// doi.org/10.1016/0032-5910(83)87009-0

Malaysian-German Chamber of Commerce and Industry (2016). Potential and challenges of confectionery products in the Malaysia market 2015. Kuala Lumpur: EU-Malaysia Chamber of Commerce and Industry (EUMCCI).

Mohamad, N.S., Abu Bakar, N., Anuar, M.S. and Tahir, S.M. (2013). Diametrical elastic relaxation of lactose -cocoa binary tablets. Particulate Science and Technology, 31(2), 186-189. https:// doi.org/10.1080/02726351.2012.686960

Mohd Radzuan, N., Anuar, M.S. and Tahir, S.M. (2020). The mixing of cohesive and flowable powder materials using a common laboratory powder mixer. Food Research, 5(Suppl. 1), 19 -24.

O’Donnel, K. and Kearsley, M.W. (2012). Sweeteners and Sugar Alternatives in Food Technology. Chichester: Wiley-Blackwell. https:// doi.org/10.1002/9781118373941

Radzali, N.S., Jaafar, N.M., Anuar, M.S. and Tahir, S.M. (2018). Compaction, mechanical strength and disintegration of palm oil empty fruit bunch (EFB) carboxymethyl cellulose (CMC) tablets. Food Research, 2(6), 520-525. https://doi.org/10.26656/ fr.2017.2(6).131

Shamjuddin, A., Anuar, M.S. and Tahir, S.M. (2014). Characteristics of tabletted roselle (Hibiscus sabdariffa linn.) with addition of sodium starch glycolate. Particulate Science and Technology, 32 (4), 384-391. https:// doi.org/10.1080/02726351.2014.880095

Shamsudin, I.S., Anuar, M.S. and Tahir, S.M. (2012). Compaction of sweet potato (Ipomoea batatas L.) and stevia rebaudiana food powders. Particulate Science and Technology, 30(2), 135-144. https:// doi.org/10.1080/02726351.2011.552098

Shamsudin, I.S., Anuar, M.S., Yusof, Y.A., Mohd. Hanif, A.H. and Tahir, S.M. (2019). Improvement in the mechanical strength of compacted urea fertilizer tablets through die wall lubrication. Pertanika Journal of Science and Technology, 27(1), 193-293.

Yaakub, N.A., Anuar, M.S. and Tahir, S.M. (2018). Compaction behaviour and mechanical strength of lactose-sodium starch glycolate and lactosecroscarmellose sodium binary tablets. IOP Conference Series: Materials Science and
Engineering, 342, $012026 . \quad$ https:// doi.org/10.1088/1757-899X/342/1/012026 